\title{
Effects of D,L-2-Hydroxy-3-Butynoic Acid, an Inhibitor of Glycolate Oxidase, on Oxalogenesis from Glycolate in vivo
}

\author{
Koji Kameda, Makoto Yanagawa and Juichi Kawamura \\ Department of Urology, Faculty of Medicine, Mie University, 2-174 Edobashi, Tsu, Mie 514-8507, Japan \\ (Received 31 May 2000; and accepted 10 July 2000)
}

\begin{abstract}
A terminal step of endogenous oxalate synthesis in mammals is the successive oxidation of glycolate to oxalate via glyoxylate in the liver. D,L-2-hydroxy-3-butynoate (NaHBA) is an irreversible inhibitor of glycolate oxidase $(\mathrm{GO})$, which is responsible for the oxidation of glycolate to glyoxylate. We examined the effect on oxalogenesis of inhibiting hepatic GO activity with NaHBA. The GO activity in the liver and the concentrations of glycolate and oxalate in the 24-h urine were determined after $10 \mathrm{mg}$ of NaHBA was given orally to male rats. After administration of NaHBA, hepatic GO activity decreased rapidly to about $20 \%$, remained low for about $10 \mathrm{~h}$, and then gradually recovered during the subsequent 12 -h period to about $50 \%$ of the original level. The NaHBA treatment increased urinary glycolate excretion by about 4 -fold, but did not significantly reduce oxalate excretion. The increase in urinary oxalate excretion after administration of glycolate, but not that after glyoxylate loading, was suppressed to about half by the NaHBA treatment. These results indicate that the partial inhibition of hepatic GO activity by NaHBA was not associated with a marked change in urinary oxalate excretion, probably because the contribution of endogenous oxalogenesis from or via glycolate was smaller than has been believed.
\end{abstract}

In mammals, oxalate is an apparently useless end product of metabolism and is mostly excreted in the urine. Since the calcium salt of oxalate is insoluble at neutral $\mathrm{pH}$, its overproduction leads to nephrolithiasis and finally to oxalosis as in the case of primary hyperoxaluria.

Although the origin of oxalate in mammals is not yet fully understood, glycolate is considered to be a major precursor, and the conversion of glycolate to oxalate is known to be achieved by successive oxidation via glyoxylate. The major enzymes associated with the terminal step of oxalogenesis include glycolate oxidase (GO), lactate dehydrogenase (LDH) and serine:

\footnotetext{
* Correspondence to Dr Makoto Yanagawa at the above address.

Tel: +81-59-231-5026, Fax: +81-59-231-5203,

E-mail: yanagawa@clin.medic.mie-u.ac.jp
}

pyruvate/alanine: glyoxylate aminotransferase (SPT/AGT). GO is a liver peroxisomal enzyme and is responsible for the oxidation of glycolate to glyoxylate $(5,12)$. In addition, this enzyme catalyzes the oxidation of glyoxylate to oxalate at least in vitro (18). LDH also catalyzes the oxidation of glyoxylate to oxalate in vitro (20). Poore et al. (17) recently proposed, based on their in vitro studies using isolated guinea-pig liver peroxisomes and purified $\mathrm{LDH}$, that cytosolic $\mathrm{LDH}$ was primarily responsible for the oxidation of glyoxylate in vivo. Although LDH has long been regarded as a cytosolic enzyme, recent studies by Baumgart et al. (3) have demonstrated that at least $0.5 \%$ of the total LDH activity in rat hepatocytes was a bona fida peroxisomal enzyme. It is therefore possible that peroxisomal LDH also contributes to the oxidation of glyoxylate to oxalate in the liver. SPT/AGT is a liver enzyme 
of dual organelle localization, being found largely in mitochondria in carnivores, entirely in peroxisomes in herbivores and man, and in both mitochondria and peroxisomes in rodents such as the rat $(15,21)$. This enzyme catalyzes conversion of glyoxylate, to glycine by transamination, and when it is missing as in the case of primary hyperoxaluria type 1 more glyoxylate is channeled into the oxalate production, finally resulting in the deposition of calcium oxalate crystals in the kidneys, bones, and other tissues (4). It is thus suggested that the formation of glyoxylate from glycolate in liver peroxisomes occurs in excess of the amount utilized for the oxidation to oxalate, and that transamination of glyoxylate to glycine catalyzed by peroxisomal SPT/AGT represents a major mechanism for the curtailment of oxalate production at least in herbivores and man. It is also known that glycolate is a normal constituent of both human and rat urine $(7,11$, $13,14)$. Since GO is the only enzyme known to react with glycolate, the utilization of glycolate may be limited by either the GO activity or by the supply of endogenously formed or ingested glycolate to liver peroxisomes. Therefore, the present study was undertaken to examine the in vivo effect on oxalogenesis of reducing the GO activity by administration of D,L-2-hydroxy-3butynoate (NaHBA), an irreversible inhibitor of GO (10).

\section{MATERIALS AND METHODS}

Determination of $G O$ activity and the effect of $N a H B A$ on it. Assay of the GO activity was performed by an enzymatic method (22) as described previously. The standard reaction mixture $(1 \mathrm{~mL})$ comprised $80 \mathrm{mM}$ sodium phosphate $(\mathrm{pH}$ 7.5), $10 \mathrm{mM}$ glycolate, and the enzyme. When the activity of crude enzyme preparations was measured, $0.4 \mathrm{mM}$ allopurinol was included in the reaction mixture to prevent oxidation of glyoxylate to oxalate by xanthine oxidase (22). The reaction was started by addition of glycolate, and after $20-60 \mathrm{~min}$ of incubation at $37^{\circ} \mathrm{C}$ under air, it was terminated by adding $0.2 \mathrm{~mL}$ of 2.7 $\mathrm{N} \mathrm{HClO}_{4}$. This was followed by neutralization with $\mathrm{KOH}$ and determination of glyoxylate formation by using LDH and NADH.

To assess the effect of NaHBA on hepatic GO activity in vitro, GO was partially purified from rat livers by ammonium sulfate fractionation and DE52 chromatography as described previously
(22), and the partially purified enzyme preparation was incubated with $10 \mathrm{mM}$ glycolate as a substrate in the absence or presence of various concentrations of NaHBA.

Male Wistar rats weighing 200-250 g were obtained from Japan SLC (Hamamatsu, Japan), and were fed a standard chow (Japan Clea Co., Tokyo, Japan). The animals were fasted for $24 \mathrm{~h}$ before use. To assess the effect of NaHBA on hepatic $\mathrm{GO}$ activity in vivo, $2 \mathrm{~mL}$ of a $5 \mathrm{mg} / \mathrm{mL}$ solution of NaHBA in $\mathrm{H}_{2} \mathrm{O}$ was administered p.o. to each rat using a stomach tube, and the rats were sacrificed after 1 to $72 \mathrm{~h}$. Then the liver was rapidly excised and homogenized in 9 vol. of 0.1 $M$ sodium citrate/phosphate $(\mathrm{pH}$ 6.1) with a Waring blender. The homogenate was subjected to sonication for $5 \mathrm{~min}$, followed by centrifugation at $16,500 \times g$ for $30 \mathrm{~min}$, and then the GO activity in the supernatant was determined in the presence of allopurinol.

All assays of GO activity were performed under conditions in which the reactions proceeded nearly linearly with respect to both time and enzyme concentration.

Determination of urinary oxalate and glycolate excretion after loading with NaHBA. Rats were given p.o. $2 \mathrm{~mL}$ of a $5 \mathrm{mg} / \mathrm{mL}$ aqueous solution of VaHBA via a stomach tube. Control rats received $2 \mathrm{~mL}$ of $\mathrm{H}_{2} \mathrm{O}$. The rats were immediately placed individually into a glass metabolic chamber for collection of 24-h urine in a glass vessel containing $70 \mu \mathrm{L}$ of $6 \mathrm{~N} \mathrm{HCl}$. Urinary glycolate and glyoxylate were determined by HPLC according to the method of Petrarulo et al. (16), using a Shimadzu HIC-6A ion chromatograph (Shimadzu Corp., Kyoto, Japan). Oxalate was determined enzymatically with oxalate oxidase (9).

Determination of the effect of $N a H B A$ on glycolate and glyoxylate metabolism in vivo. Rats were divided into two groups, a glycolateloaded group (group 1) and a glyoxylate-loaded group (group 2). Each group was further divided into two subgroups, a NaHBA-treated subgroup (B) and an untreated subgroup (A). Each subgroup comprised from 5 to 8 rats. Animals of all 4 subgroups were fasted for $24 \mathrm{~h}$ before the experiment. At 0-time ( $24 \mathrm{~h}$ after the start of fasting) NaHBA-treated (B) and untreated (A) subgroups were given p.o. $2 \mathrm{~mL}$ of a $5 \mathrm{mg} / \mathrm{mL}$ aqueous solution of NaHBA and $2 \mathrm{~mL}$ of $\mathrm{H}_{2} \mathrm{O}$, respectively. Twenty-four hours after the NaHBA administration $2 \mathrm{~mL}$ of $1 \mathrm{M}$ sodium glycolate or $1 \mathrm{M}$ 
sodium glyoxylate was orally administered to rats of groups 1 and 2, respectively. Rats were immediately placed individually in a glass metabolic chamber for collection of 24-h urine, after which the liver was removed and homogenized for the assay of GO activity.

Statistical analysis. Statistical analysis was done with Welch test.

Materials. NaHBA was purchased from Tokyo Kasei Organic Chemicals (Tokyo, Japan), DE52 was from Whatman Ltd. (Kent, England), and sodium glycolate and sodium glyoxylate were from Wako Pure Chemicals (Osaka, Japan). The sources of reagents and enzymes for the determination of oxalate were described previously (9).

\section{RESULTS}

In vitro inhibition of rat liver $G O$ by $N a H B A$. The apparent $\mathrm{K}_{\mathrm{m}}\left(\mathrm{K}_{\mathrm{m}}\right.$ determined with incubation under air) of rat liver GO was estimated in the present study to be about $0.3 \mathrm{mM}$ for glycolate and $4.6 \mathrm{mM}$ for glyoxylate, in fairly good agreement with Asker and Davies (2) and with our previous study (22). NaHBA effectively inhibited GO activity under the assay conditions used, achieving approximately $92 \%$ inhibition when 0.6 $\mathrm{mM}$ NaHBA was included in the reaction mixture (Fig. 1).

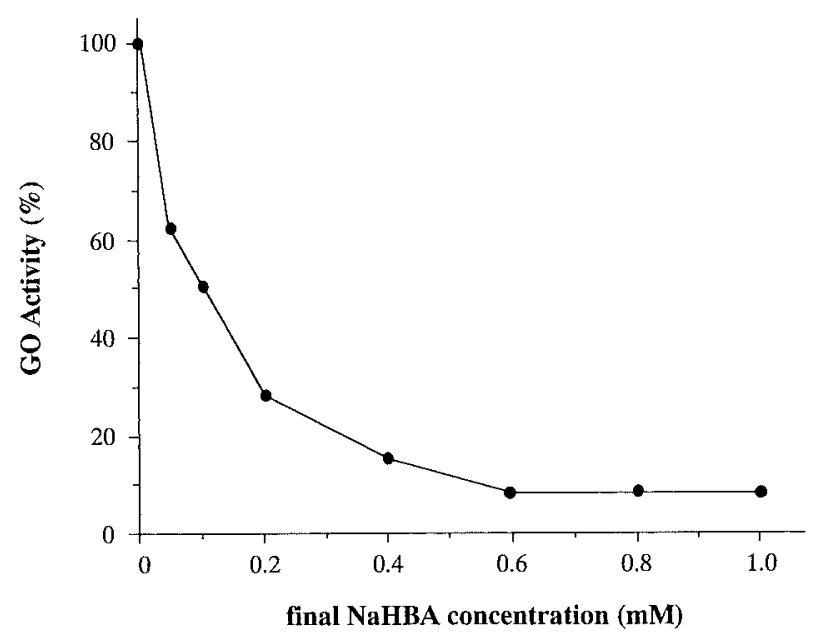

Fig. 1 Effect of NaHBA on hepatic GO activity in vitro. A partially purified enzyme preparation from rat liver was incubated with $10 \mathrm{mM}$ glycolate as a substrate in the absence or presence of various concentrations of NaHBA as described under "Materials and Methods".
In vivo inhibition of rat liver $G O$ by $N a H B A$. When $10 \mathrm{mg}$ of NaHBA was given orally, the activity of GO in the liver decreased to about one-fifth of the original level after $2 \mathrm{~h}$ and remained at the 15-20\% level for about $10 \mathrm{~h}$. Then the GO activity slowly recovered to about $45 \%$ and $57 \%$ of the control value after $24 \mathrm{~h}$ and $48 \mathrm{~h}$, respectively (Fig. 2).

Urinary excretion of oxalate and glycolate after loading of NaHBA. As shown in Table 1, urinary excretion of oxalate and glycolate in 24 h-fasted rats was determined to be approximately 1.6 and $5.3 \mu \mathrm{mol} / \mathrm{d}$, respectively. Thus, fasted rats were producing more than $5 \mu \mathrm{mol}$ of glycolate daily and converting part of it to oxalate. The decline of the GO activity after NaHBA administration resulted in about 4 -fold increase in urinary glycolate excretion, but unexpectedly oxalate excretion did not show a significant change.

In vivo effect of NaHBA on glycolate and glyoxylate metabolism. When $2 \mathrm{mmol}$ of glycolate was administered orally to $24 \mathrm{~h}$-fasted rat (200 $-250 \mathrm{~g}$ ), more than $65 \%$ of the dose was excreted in the urine as unchanged glycolate during the subsequent $24 \mathrm{~h}$ period (Table 1). It was thus suggested that capacity of hepatic GO was limited and not sufficient to oxidize the oral glycolate load or hepatic uptake of glycolate was limited under these conditions. Nevertheless, oxalate excretion was increased by more than 10 -fold after the glycolate loading (Tables 1 and 2). Although glycolate is excreted in the urine of

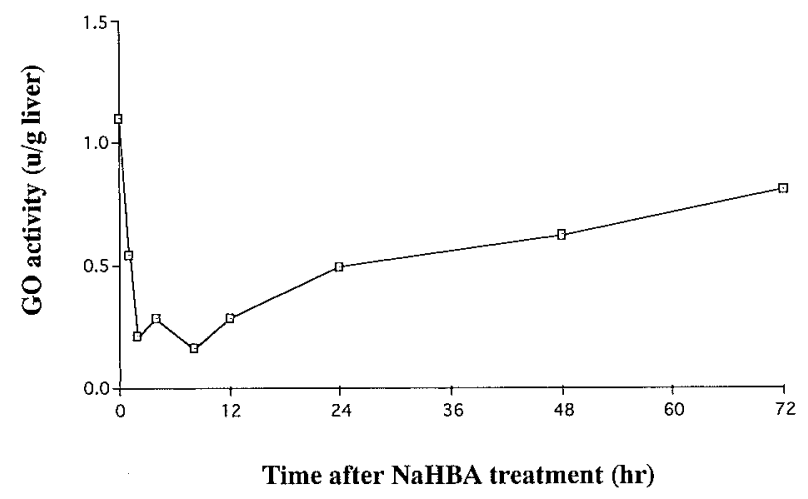

Fig. 2 Inhibition of hepatic GO by the NaHBA treatment. Experimental details are given in "Materials and Methods". One unit of GO represents the activity which catalyzes the formation of $1 \mu \mathrm{mol}$ of glyoxylate per min under the standard assay conditions. 
normal rats, it is possible that the supply of glycolate is also a limiting factor for oxalogenesis, and when glyoxylate is produced from glycolate in excess of the capacity of SPT/ AGT to transaminate to glycine it overflows into the oxalate production. Loading with $2 \mathrm{mmol}$ of glyoxylate also increased the urinary excretion of both oxalate and glycolate by 30 - to 40 -fold. The oxidation of glycolate to glyoxylate in hepatic peroxisomes does not appear to be very efficient as judged from the urinary excretion of glycolate which was more than that of oxalate in both 24 $\mathrm{h}$-fasted control rats and glycolate-loaded rats (Tables 1 and 2).

In experiments shown in Table 2 , oxalate precursors were also loaded to rats which received NaHBA $24 \mathrm{~h}$ before and whole GO activity had been reduced to about half of the control value (cf. Fig. 2). The NaHBA treatment reduced by about $50 \%$ the increase in oxalate excretion

Table 1. Urinary excretion of oxalate and glycolate after loading with NaHBA

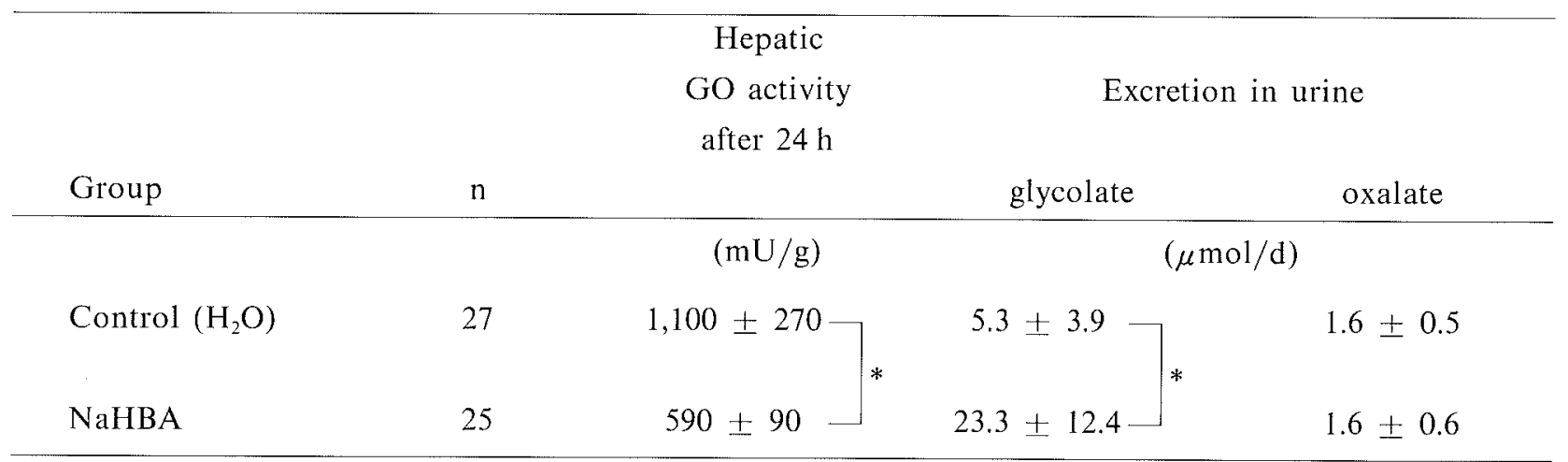

Values are presented as the mean \pm S.D. $n:$ the number of experiments.

*: $P<0.0001$ as compared with the control $\left(\mathrm{H}_{2} \mathrm{O}\right)$, respectively.

Experimental details are given in "Materials and Methods".

Table 2. Effect of NaHBA on urinary excretion of oxalate and glycolate after glycolate or glyoxylate loading

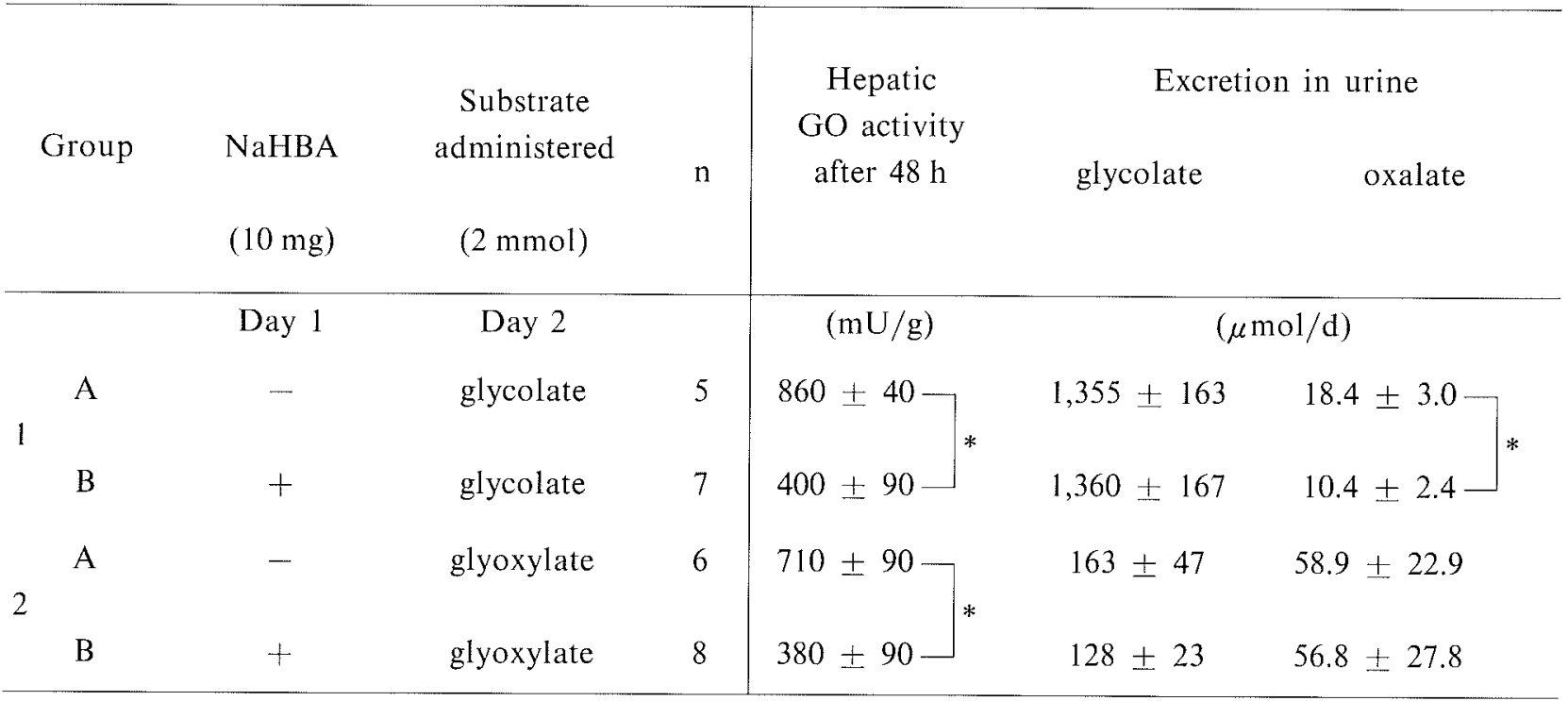

Values are presented as the mean \pm S.D.

$\mathrm{n}$ : the number of experiments

*: $P<0.001$ as compared with the respective subgroup A.

Experimental details are given in "Materials and Methods". 
caused by glycolate loading, but not that caused by glyoxylate loading. These results suggest that GO catalyzes glycolate oxidation but does not contribute appreciably to glyoxylate oxidation in vivo, and the reduction in the oxalate excretion by NaHBA is accounted for by the decreased rate of glyoxylate formation (Table 2). Excretion of glyoxylate in the urine was not detectable in any of the subgroups, including group 2 which received oral administration of $2 \mathrm{mmol}$ of glyoxylate.

\section{DISCUSSION}

In the present study, NaHBA, a powerful irreversible inhibitor of GO, was administered to rats to assess its effect on the urinary excretion of oxalate. Unfortunately, it was not possible to completely abolish the GO activity in the liver. Under the experimental conditions selected in which $10 \mathrm{mg}$ of NaHBA was orally administered to $200-250 \mathrm{~g}$ rats, the hepatic GO activity decreased rapidly to about one-fifth of the original level, and the low activity was maintained for about $10 \mathrm{~h}$. Then the GO activity gradually recovered to about $50 \%$ of the original level after $24 \mathrm{~h}$. The area under the activity vs. time curve (AUC) during $24 \mathrm{~h}$ after the NaHBA treatment and that during subsequent $24 \mathrm{~h}$ were about $30 \%$ and $50 \%$, respectively. The NaHBA administration to $24 \mathrm{~h}$-fasted rats caused an approximately 4-fold increase in the urinary excretion of glycolate, but did not affect significantly the oxalate excretion. In this context, it was interesting that $24 \mathrm{~h}$-fasted rats excreted about $5 \mu$ moles of glycolate in a day, suggesting inefficient utilization of glycolate by GO. Upon oral loading with $2 \mathrm{mmol}$ of glycolate, the urinary excretion of oxalate was increased about 10-fold, and the increase caused by glycolate loading was reduced to about half by the NaHBA treatment. It appears that the formation of glyoxylate from glycolate in vivo is also limited by the supply of glycolate to GO and the contribution of glycolate-derived oxalate to urinary oxalate is much smaller than has been thought. Rooney et al. (19) also reported that chronic oral administration to ethylene glycol fed rats of the 4-substituted 3-hydroxy-1Hpyrrole-2,5-dione derivatives as an inhibitors of GO was shown to effect a significant reduction in urinary oxalate levels over a 58 -day period but there has been no significant effect in normal rats. Therefore, it would be interesting to know the $K_{m}$ of $\mathrm{GO}$ for glycolate at the cellular level of $\mathrm{O}_{2}$ and the concentration of glycolate in hepatocytes or preferably in liver peroxisomes. Harris and Richardson (6) reported that $\left[1-{ }^{14} \mathrm{C}\right]$ glycolate administered orally to rats was rapidly absorbed from the intestinal tract, and at low dosage levels as much as $50 \%$ of the dose administered is metabolized to ${ }^{14} \mathrm{CO}_{2}$, whereas the recovery of ${ }^{14} \mathrm{C}$ as ${ }^{14} \mathrm{C}$-oxalate and unmetabolized ${ }^{14} \mathrm{C}$-glycolate in the urine was about $3 \%$ each. Since the most likely metabolic pathway of $\left[1-{ }^{14} \mathrm{C}\right]$ glycolate to ${ }^{14} \mathrm{CO}_{2}$ involves its oxidation to $\left[1-{ }^{14} \mathrm{C}\right]$ glyoxylate by GO, followed by SPT / AGT-catalyzed transamination to $\left[1-{ }^{14} \mathrm{C}\right]$ glycine and tetrahydrofolatedependent oxidation of the latter to ${ }^{14} \mathrm{CO}_{2}$ by mitochondrial glycine cleavage enzyme system, it is highly possible that most of the glyoxylate formed from glycolate is converted to glycine and only a very small amount is oxidized to oxalate. The urinary excretion of a small but significant amount of glycolate despite the efficient metabolism in $24 \mathrm{~h}$-fasted rats of orally administered $\left[1-{ }^{14} \mathrm{C}\right]$ glycolate remains to be explained.

It has long been accepted that most of oxalate in urine was derived from its synthesis in the liver (40-50\%), and ascorbic acid degradation (40$50 \%$ ), and contribution of oxalate in the diet was only $10-20 \%$ (1). However, Holmes et al. (8) recently found, after feeding two individuals with an oxalate-free diet for 7 days, that dietary oxalate accounted for as much as $65-70 \%$ of the oxalate excreted in the urine. The latter data are also compatible with the possibility raised in the present study that contribution to urinary oxalate of endogenous oxalogenesis from or via glycolate is much smaller than has been believed.

This study also showed that NaHBA is very toxic to rats and is fatal when more than $15 \mathrm{mg}$ is administered or when a $10 \mathrm{mg}$ dose is administered twice or three times at 24-h intervals. Even after a single dose of $10 \mathrm{mg}$, the urine volume increased from $3-5 \mathrm{~mL} /$ day to about $25 \mathrm{~mL} /$ day. Microscopic observation of kidney slices revealed that epithelial cells in the collecting ducts had become flattened, consistent with the increase in urine volume, but the glomeruli appeared to be largely intact. Hepatocytes were slightly swollen and the sinusoids were engorged, but no other obvious liver damages were observed. It was therefore unlikely that more oxalate was excreted in the urine due to the toxic effects of NaHBA. 


\section{Acknowledgments}

The authors are indebted to Prof. Arata Ichiyama (First Department of Biochemistry, Hamamatsu University School of Medicine) for his advice and help in preparation of this manuscript. This work was supported in part by Grant-in-Aid for Scientific Research (11671548) from the Ministry of Education, Science and Culture of Japan and a research grant from Sankyo Co., LTD. Japan.

\section{REFERENCES}

1. Archer H. E., Dormer A. E., Scowen E. F. and Watts R. W. E. (1957) Studies on the urinary excretion of oxalate by normal subjects. Clin. Sci. 16, 405-411.

2. Asker H. and Davies D. (1983) Purification of rat liver enzymes involved in the oxidation of glyoxylate. Biochim. Biophys. Acta 761, 103-108.

3. Baumgart E., Fahimi H. D., Stich A. and Volkl A. (1996) L-lactate dehydrogenase $\mathrm{A} 4$ - and $\mathrm{A} 3 \mathrm{~B}$ isoforms are bona fide peroxisomal enzymes in rat liver. Evidence for involvement in intraperoxisomal NADH reoxidation. $J$. Biol. Chem. 271, 3846-3855.

4. Danpure C. J. and Purdue P. E. (1995) Primary hyperoxaluria. In: C. R. Scriver, A. L. Beaudet, W. S. Sly and D. Valle, ed. The Metabolic and Molecular Basis of Inherited Disease. New York: McGraw-Hill: pp.2385-2424.

5. De Duve C. and Baudhuin P. (1966) Peroxisomes (microbodies and related particles). Physiol. Rev. 46, 323-357.

6. Harris K. S. and Richardson K. E. (1980) Glycolate in the diet and its conversion to urinary oxalate in the rat. Invest. Urol. 18, 106-109.

7. Hockaday T. D. R., Fredric E. W., Clayton J. E. and Smith L. H., Jr (1965) Studies on primary hyperoxaluria II. Urinary oxalate, glycolate, and glyoxylate measurement by isotope dilution method. J. Lab. Clin. Med. 65, 677 $-687$.

8. Holmes R. P., Goodman H. O. and Assimos D. G. (1995) Dietary oxalate and its intestinal absorption. Scanning. Microsc. 9, 1109-1118; discussion 1118-1120.

9. Ichiyama A., Nakai E., Funai T., Oda T. and Katafuchi R. (1985) Spectrophotometric determination of oxalate in urine and plasma with oxalate oxidase. $J$. Biochem. (Tokyo) 98, 1375-1385.

10. Jewess P. J., Kerr M. W. and Whitaker D. P. (1975) Inhibition of glycollate oxidase from pea leaves. FEBS
Lett. 53, 292-296.

11. Kasidas G. P. and Rose G. A. (1979) A new enzymatic method for the determination of glycollate in urine and plasma. Clin. Chim. Acta 96, 25-36.

12. Kun E.Dechary J. M. and Pitot M. (1954) The oxidation of glycolic acid by a liver enzyme. J. Biol. Chem. 210, 269280.

13. Marangella M., Petrarulo M., Vitale C., Cosseddu D. and Linari F. (1992) Plasma and urine glycolate assays for differentiating the hyperoxaluria syndromes. J. Urol. 148, 986-989.

14. Metzger R. P., Sauerheber R. D., Lyons S. A. and Westall J. R. (1975) The effect of streptozotocin diabetes on the levels of glycolate and lactate excreted in rat urine. Arch. Biochem. Biophys. 169, 555-559.

15. Noguchi T. and Takada Y. (1978) Peroxisomal localization of serine:pyruvate aminotransferase in human liver. $J$. Biol. Chem. 253, 7598-7600.

16. Petrarulo M., Pellegrino S., Bianco O., Marangella M., Linari F. and Mentasti E. (1989) Derivatization and high-performance liquid chromatographic determination of urinary glycolic acid [published erratum appears in $J$. Chromatogr: 1989 Jun 23;472(2):450]. J. Chromatogr. 465, 87-93.

17. Poore R. E., Hurst C. H., Assimos D. G. and Holmes R. P. (1997) Pathways of hepatic oxalate synthesis and their regulation. Am. J. Physiol. 272, C289-294.

18. Richardson K. E. and Torbert N. E. (1961) Oxidation of glyoxylic acid to oxalic acid by glycolic acid oxidase. $J$. Biol. Chem. 236, 1280-1284.

19. Rooney C. S., Randall W. C., Streeter K. B., Ziegler C., Cragoe E. J., Jr., Schwam H., Michelson S. R., Williams H. W., Eichler E., Duggan D. E., Ulm E. H. and Noll R. M. (1983) Inhibitors of glycolic acid oxidase. 4-Substituted 3-hydroxy-1H-pyrrole-2,5-dione derivatives. J. Med. Chem. 26, 700-714.

20. Sawaki S., Hattori H. and Yamada K. (1967) Glyoxylate dehydrogenase activity of lactate dehydrogenase. J. Biochem. (Tokyo) 62, 263-268.

21. Takada Y. and Noguchi T. (1982) Subcellular distribution, and physical and immunological properties of hepatic alanine: glyoxylate aminotransferase isoenzymes in different mammalian species. Comp. Biochem. Physiol. [B] 72, 597-604.

22. Yanagawa M., Maeda-Nakai E., Yamakawa K., Yamamoto I., Kawamura J., Tada S. and Ichiyama A. (1990) The formation of oxalate from glycolate in rat and human liver. Biochim. Biophys. Acta 1036, 24-33. 